\title{
Near-Infrared Spectroscopy Can Predict the Onset of Cerebral Hyperperfusion Syndrome after Carotid Endarterectomy
}

\author{
C.W.A.Pennekamp ${ }^{a} \quad$ R.V. Immink ${ }^{b} \quad$ H.M. den Ruijter ${ }^{\mathrm{e}} \quad$ L.J. Kappelle ${ }^{c} \quad$ C.M. Ferrier ${ }^{d}$ \\ M.L. Bots ${ }^{\mathrm{e}}$ W.F. Buhre ${ }^{\mathrm{b}}$ F.L. Moll ${ }^{\mathrm{a}}$ G.J. de Borst ${ }^{\mathrm{a}}$ \\ Departments of a Vascular Surgery, ${ }^{\mathrm{b}}$ Anesthesiology, ${ }^{\mathrm{C}}$ Neurology and ${ }^{\mathrm{d}} \mathrm{Clinical}$ Neurophysiology, and $\mathrm{e}$ Julius Center for \\ Health Sciences and Primary Care, University Medical Center Utrecht, Utrecht, The Netherlands
}

\section{Key Words}

Near-infrared spectroscopy $\cdot$ Cerebral hyperperfusion syndrome $\cdot$ Carotid endarterectomy

\begin{abstract}
Background: Cerebral hyperperfusion syndrome (CHS) after carotid endarterectomy (CEA) is a potential life-threatening complication. Therefore, early identification and treatment of patients at risk is essential. CHS can be predicted by a doubling of postoperative transcranial Doppler (TCD)-derived mean middle cerebral artery blood velocity $\left(V_{\text {mean }}\right)$ compared to preoperative values. However, in approximately $15 \%$ of CEA patients, an adequate TCD signal cannot be obtained due to an insufficient temporal bone window. Moreover, the use of TCD requires specifically skilled personnel. An alternative and promising technique of noninvasive cerebral monitoring is relative frontal lobe oxygenation $\left(\mathrm{rSO}_{2}\right)$ measured by near-infrared spectroscopy (NIRS), which offers on-line information about cerebral oxygenation without the need for specialized personnel. In this study, we assess whether NIRS and perioperative TCD are related to the onset CHS following CEA. Methods: Patients who underwent CEA under general anesthesia and had a sufficient TCD window were prospectively included. The $V_{\text {mean }}$ and $\mathrm{rSO}_{2}$ measured before induction of anesthesia were compared to measure-
\end{abstract}

(C) 2012 S. Karger AG, Basel

$1015-9770 / 12 / 0344-0314 \$ 38.00 / 0$

Fax +4161306 1234

E-Mail karger@karger.ch

www.karger.com
Accessible online at:

www.karger.com/ced ments performed in the first postoperative hour $\left(\Delta V_{\text {mean }}\right.$ $\Delta \mathrm{rSO}_{2}$, respectively). Logistic regression analysis was performed to determine the relationship between $\Delta V$ and $\Delta \mathrm{rSO}_{2}$ and the occurrence of CHS. Subsequently, receiver operating characteristic (ROC) curve analysis was used to determine the optimal cutoff values. Diagnostic values were shown as positive and negative predictive values (PPV and NPV). $\boldsymbol{R e}$ sults: In total, 151 patients were included, of which 7 patients developed CHS. The $\Delta V_{\text {mean }}$ and $\Delta \mathrm{rSO}_{2}$ differed between $\mathrm{CHS}$ and non-CHS patients (median, interquartile range), i.e. $74 \%(67-103)$ versus $16 \%$ ( -2 to 41$), p=0.001$, and $7 \%(4-15)$ versus $1 \%$ ( -6 to 7$), p=0.009$, respectively. The mean arterial blood pressure did not change. Postoperative $\Delta V_{\text {mean }}$ and $\Delta \mathrm{rSO}_{2}$ were significantly related to the occurrence of $\mathrm{CHS}$ [odds ratio (OR) 1.40 (95\% Cl 1.02-1.93) per 30\% increase in $V_{\text {mean }}$ and $\mathrm{OR} 1.82(95 \% \mathrm{Cl} 1.11-2.99)$ per $5 \%$ increase in $\mathrm{rSO}_{2}$ ]. ROC curve analysis showed an area under the curve of 0.88 ( $p=0.001$ ) for $\Delta V_{\text {mean }}$ and an optimal cutoff value of $67 \%$ increase (PPV 38\% and NPV 99\%), and an area under the curve of $0.79(p=0.009)$ for $\Delta \mathrm{rSO}_{2}$ and an optimal cutoff value of $3 \% \mathrm{rSO}_{2}$ increase (PPV $11 \%$ and NPV 100\%). The combination of both monitoring techniques provided a PPV of $58 \%$ and an NPV of $99 \%$. Conclusions: Both TCD and NIRS measurements can be used to safely identify patients not at risk of developing CHS. It appears that NIRS is a good alternative when a TCD signal cannot be obtained.

Copyright $\odot 2012$ S. Karger AG, Base

G.J. de Borst, $\mathrm{MD}, \mathrm{PhD}$

UMCU, Department of Vascular Surgery (G04.129)

PO Box 85500

NL-3508 GA Utrecht (The Netherlands)

E-Mail G.J.deBorst-2@umcutrecht.nl 


\section{Background}

Perioperative cerebrovascular complications of carotid endarterectomy (CEA) can be divided into intra- and postoperative complications, depending on the time of onset. Intraoperative adverse events, mostly caused by thromboembolic events or hypoperfusion [1], have significantly declined following the introduction of intraoperative cerebral monitoring [2-4], whereas the postoperative rate of cerebrovascular complications remained more or less stable with approximately 3\% [2]. Besides local thrombosis at the level of the endarterectomy or thromboembolism, cerebral hyperperfusion syndrome (CHS) is an important postoperative complication.

CHS, defined as a cerebral hyperperfusion in addition to neurological symptoms, occurs in approximately $3-5 \%$ of patients undergoing a CEA procedure and is potentially life threatening [5].

When not recognized timely and treated adequately, CHS can lead to intracerebral hemorrhage, the most feared complication associated with a mortality of $40 \%$, and therefore warrants early identification of patients at risk [6]. Currently, postoperative transcranial Doppler (TCD) monitoring is considered the gold standard in CHS prediction. A TCD value which is the double of preoperative middle cerebral artery (MCA) mean blood velocity $\left(V_{\text {mean }}\right)$ is associated with onset of CHS in about $40 \%$ of patients and can reliably exclude patients at risk of developing CHS [7]. However, in 10-15\% of CEA patients, an adequate TCD signal cannot be obtained because of an insufficient temporal bone window. At present, for this subgroup of patients, there is no reliable alternative monitoring tool to predict CHS. As a consequence, patients at high risk might be missed by the current monitoring strategy, while patients might be incorrectly identified as high risk for CHS leading to superfluous treatment and additional costs.

An alternative approach is perioperative monitoring of the frontal lobe oxygenation of the brain $\left(\mathrm{rSO}_{2}\right)$ with near-infrared spectroscopy (NIRS). This technique may be a promising alternative cerebral monitoring technique since it is easy to apply, applicable in all patients and relatively low in costs. However, the existing evidence on perioperative use of NIRS in relation to the onset of CHS is limited [8].

In the present study, we questioned whether NIRS could be used for identification of patients at risk of developing CHS. Therefore, we prospectively gathered NIRSmeasured $\mathrm{rSO}_{2}$ before, during and after CEA and related NIRS and TCD to the development of CHS following CEA.

\section{Methods}

\section{Patients}

This study was designed as a single-center cohort study. Patients who underwent CEA between February 2009 and June 2011 in the University Medical Center Utrecht and had a temporal window suitable for TCD monitoring were prospectively included. The severity of the carotid artery stenosis on preoperative imaging by computed tomography angiography or magnetic resonance angiography was categorized on a 4 -point scale: $<50 \%, 50-70 \%$, $70-99 \%$ stenosis or occlusion.

\section{Measurements (fig. 1)}

One day before surgery, baseline oscillometric blood pressure (BP) and bilateral $V_{\text {mean }}$ were measured. Baseline $\mathrm{rSO}_{2}$ was determined bilaterally before induction of anesthesia and continued till the end of surgery. Peroperatively and in the recovery ward, intra-arterial BP was monitored through a catheter $(1.1 \mathrm{~mm} \mathrm{ID}$, 20 gauge) placed in the radial artery. Intraoperative $V_{\text {mean }}$ monitoring was started after induction, but before incision, and continued till the end of surgery. Postoperative TCD and NIRS measurements were performed for a period of $20 \mathrm{~min}$ in the first postoperative hour.

\section{Transcranial Doppler}

For measurement of the $V_{\text {mean }}$ in the MCA, a pulsed Doppler transducer (DWL Multidop X4, Sipplingen, Germany) gated at a focal depth of 45-60 $\mathrm{mm}$ was placed over the temporal bone to insonate the main stem of the ipsilateral MCA and $V_{\text {mean }}$ was recorded continuously.

\section{Near-Infrared Spectroscopy}

The $\mathrm{rSO}_{2}$ measurement was performed using Invos Cerebral Oximeter (Somanetics Corporation, Troy, Mich., USA) with the aid of two sensors placed on the forehead.

\section{Intraoperative Management}

After application of routine monitoring devices (ECG and pulse oximetry), induction of anesthesia was achieved with sufentanil $(0.3-0.7 \mu \mathrm{g} / \mathrm{kg})$, propofol $(0.5-2.0 \mathrm{mg} / \mathrm{kg})$ and rocuronium $(0.3-0.5 \mathrm{mg} / \mathrm{kg})$. Anesthesia was maintained using sevoflurane, with a minimum alveolar concentration of $0.5-1$. Before cross-clamping the carotid artery, 5,000 $\mathrm{U}$ of heparin was given intravenously.

The CEA was performed by an experienced vascular surgeon or by a vascular trainee under supervision in a standardized way. An intraluminal shunt was used selectively in case of electroencephalographic (Micromed Inc., Treviso, Italy) asymmetry.

\section{Postoperative Management}

Postoperatively, patients stayed in the recovery ward for continuous BP monitoring for at least $6 \mathrm{~h}$. After the postoperative NIRS and TCD measurements had been performed, patients with a systolic BP >160 $\mathrm{mm} \mathrm{Hg}$, a BP of $20 \%$ above the preoperative BP, a postoperative $V_{\text {mean }}>100 \%$ compared to preoperative $V_{\text {mean }}$, or an absolute $V_{\text {mean }}>120 \mathrm{~cm} \cdot \mathrm{s}^{-1}$ with or without symptoms were treated with intravenous infusion of labetalol $\left(5-20 \mathrm{mg} \cdot \mathrm{h}^{-1}\right)$ to decrease BP and/or $V_{\text {mean }}$. After $6 \mathrm{~h}$, patients were moved to the general ward. However, if BP was not controlled appropriately or if signs of CHS were present during the 6-hour time frame in the 
Table 1. Patient characteristics of all patients and according to the onset of CHS

\begin{tabular}{lcccc}
\hline Variable & $\begin{array}{l}\text { All patients } \\
(\mathrm{n}=151)\end{array}$ & $\begin{array}{l}\text { CHS } \\
(\mathrm{n}=7)\end{array}$ & $\begin{array}{l}\text { Non-CHS } \\
(\mathrm{n}=144)\end{array}$ & p value \\
\hline Male gender & $117(78)$ & $5(71)$ & $112(78)$ & 0.695 \\
Right side & $63(42)$ & $3(43)$ & $60(42)$ & 0.950 \\
Median age (IQR), years & $70(64-78)$ & $59(54-69)$ & $70(64-78)$ & 0.079 \\
History of CEA & & & \\
$\quad$ Ipsilateral & $1(1)$ & 0 & $1(1)$ & 0.825 \\
$\quad$ Contralateral & $17(11)$ & $1(14)$ & $16(11)$ & 0.795 \\
Symptomatic indication & $133(88)$ & $6(86)$ & $127(88)$ & 0.843 \\
Degree of ipsilateral stenosis & $9(6)$ & $1(14)$ & $8(6)$ & 0.341 \\
$\quad 50-70 \%$ & $142(94)$ & $6(86)$ & $136(94)$ & 0.300 \\
$\quad>70 \%$ & $72(48)$ & $2(29)$ & $70(49)$ & 0.869 \\
Degree of contralateral stenosis & $25(17)$ & $1(14)$ & $24(17)$ & 0.348 \\
$\quad<50 \%$ & $24(16)$ & $2(29)$ & $22(15)$ & 0.889 \\
$\quad 50-70 \%$ & $19(13)$ & $1(14)$ & $18(13)$ & 0.465 \\
$\quad 70-99 \%$ & $11(7)$ & $1(14)$ & $10(7)$ & 0.138 \\
$\quad$ Occlusion & $17(11)$ & $2(29)$ & $15(10)$ & 0.655 \\
$\quad$ Unknown & $4(3)$ & 0 & $4(3)$ & 0.825 \\
Peroperative shunt use & $1(1)$ & 0 & $1(1)$ & 0.001 \\
Perioperative stroke & $32(21)$ & $7(100)$ & $25(17)$ & 0.825 \\
Perioperative transient ischemic attack & $1(1)$ & 0 & $1(1)$ & \\
Postoperative hypertension & & &
\end{tabular}

Figures in parentheses are percentages, unless otherwise determined.

recovery ward, patients were transferred to the medium care unit for continuous monitoring and intravenous therapy.

\section{Definition of CHS}

CHS was defined as the postoperative occurrence of headache, confusion, seizures, focal neurological deficits or an intracranial hemorrhage, in addition to TCD-registered postoperative cerebral hyperperfusion $\left(>100 \%\right.$ increase of the preoperative $V_{\text {mean }}$ or an absolute $\left.V_{\text {mean }}>120 \mathrm{~cm} \cdot \mathrm{s}^{-1}\right)$.

\section{Data Analysis}

The BP signal and the envelope curve of the TCD spectrum were $\mathrm{A} / \mathrm{D}$ converted at $100 \mathrm{~Hz}$, while bilateral frontal lobe $\mathrm{rSO}_{2}$ was determined at $0.14 \mathrm{~Hz}$. To calculate the mean arterial blood pressure (MAP) and $V_{\text {mean }}$, the diastolic pressure or velocity, respectively, was multiplied by 2 and added to the systolic pressure or velocity. Subsequently, the results were dived by 3 .

A 30-second averaged value of MAP, $V_{\text {mean }}$ and $\mathrm{rSO}_{2}$ was calculated at the following time points: baseline, preclamping, postclamping and postoperative. Subsequently, relative differences between baseline and postoperative MAP, $V_{\text {mean }}$ and $\mathrm{rSO}_{2}$ and between pre- and postclamping MAP, $V_{\text {mean }}$ and $\mathrm{rSO}_{2}$ were defined as $\Delta$ MAP, $\Delta V_{\text {mean }}$ and $\Delta \mathrm{rSO}_{2}$ respectively.

\section{Statistical Analysis}

Data are presented as median and interquartile range (IQR). The Wilcoxon signed rank test was used to compare the different measurements. To calculate the differences between CHS and non-CHS patients, the Mann-Whitney $U$ test was used. A p value $<0.05$ was considered significant. To determine the relationship between $\Delta V_{\text {mean }}$ and $\Delta \mathrm{rSO}_{2}$ and outcome, logistic regression analysis was performed. The optimal cutoff point of both $\Delta V_{\text {mean }}$ and $\Delta \mathrm{rSO}_{2}$ in relation to the onset of CHS was chosen using the receiver operating characteristic (ROC) curve and Youden's index $($ sensitivity + specificity -1$)$. Predictive values are shown as positive predictive value (PPV) and negative predicative value (NPV).

\section{Results}

\section{Patient Characteristics (table 1)}

Within the study time frame, 294 patients underwent CEA. Because of logistic reasons, 151 of these patients were included in this study, with a median age of 70 years (IQR 64-78). The 30-day death/stroke rate was 3\%. One patient died 13 days after surgery, because of vegetative endocarditis, without cerebrovascular complications. Seven patients (5\%) developed CHS, none of them suffering focal neurological sequelae and all 7 patients fully recovered. All CHS patients developed hypertension prior to the development of CHS. 


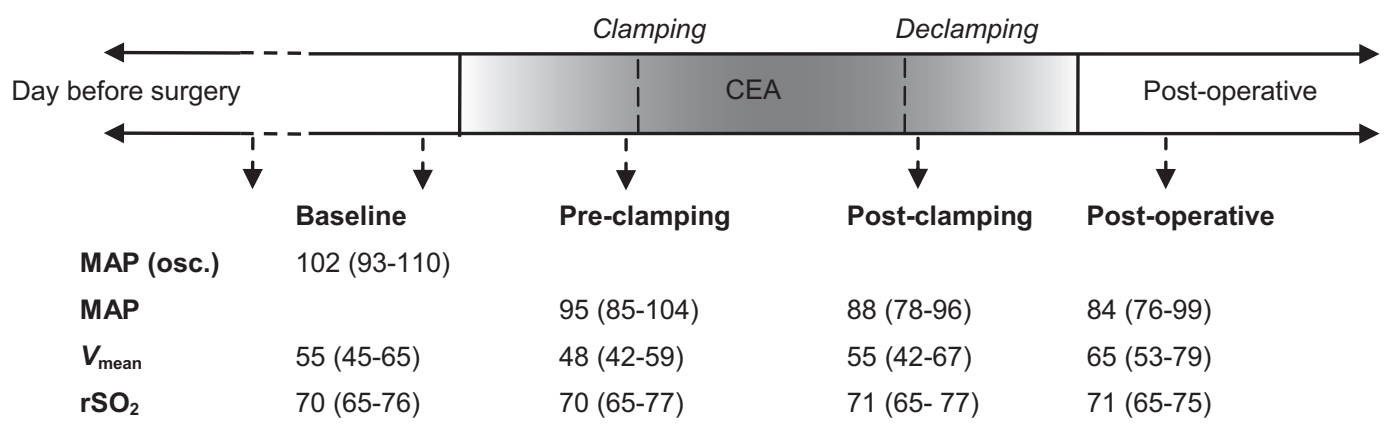

Fig. 1. Time frame. At the following time points, MAP ( $\mathrm{mm} \mathrm{Hg})$, $V_{\text {mean }}\left(\mathrm{cm} \cdot \mathrm{s}^{-1}\right)$ and $\mathrm{rSO}_{2}(\%)$ were recorded and calculated. At baseline, MAP was measured using an oscillometric (osc.) method. Transition from white turns to gray indicates anesthetizing of the patient. $\mathrm{n}=151$; data are shown as median (IQR). Baseline

values: 1 day before surgery. Preclamping values: averaged value of a 30-second measurement, 30 s before preclamping. Postclamping values: averaged value of 30 -second measurement, 3 min after declamping. Postoperative values: averaged value of 30 -second measurement, in the first postoperative hour.

Hemodynamic and Cerebral Measurements (fig. 1; tables 2, 3)

Intraoperatively, MAP decreased from $95 \mathrm{~mm} \mathrm{Hg}(85-$ 104) before cross-clamping the carotid artery to $88 \mathrm{~mm}$ Hg (IQR 78-96 mm Hg) (p < 0.001) after declamping. $V_{\text {mean }}$ increased from $48 \mathrm{~cm} \cdot \mathrm{s}^{-1}$ (IQR 42-59) to $55 \mathrm{~cm} \cdot \mathrm{s}^{-1}$ (IQR 42-67), $\mathrm{p}<0.001$. Three patients had an intraoperative $\Delta V_{\text {mean }}$ of $>100 \%$; none of them developed CHS. $\mathrm{rSO}_{2}$ did not change significantly after declamping the carotid artery.

$\Delta \mathrm{rSO}_{2}$ did not differ between patients with and without an intraoperative $\Delta V$ of $>100 \%$. Intraoperative $\Delta \mathrm{MAP}, \Delta V_{\text {mean }}$ and $\Delta \mathrm{rSO}_{2}$ did not differ significantly between patients who did or did not develop CHS.

Postoperatively, MAP decreased from $102 \mathrm{~mm} \mathrm{Hg}$ (IQR 93-110) preoperatively to $84 \mathrm{~mm} \mathrm{Hg}$ (IQR 76-99) after surgery $(\mathrm{p}=0.001)$, while $V_{\text {mean }}$ increased from 55 $\mathrm{cm} \cdot \mathrm{s}^{-1}$ (IQR 45-65) to $65 \mathrm{~cm} \cdot \mathrm{s}^{-1}$ (IQR 53-79), $\mathrm{p}<0.001$, in combination with a stable $\mathrm{rSO}_{2}$, being $70 \%$ (IQR 6576) versus $71 \%$ (IQR 65-75), $\mathrm{p}=0.340$.

Pre- and postoperative MAP did not differ between $\mathrm{CHS}$ and non-CHS patients. However, patients who developed CHS had both a larger $\Delta V_{\text {mean }}$ and a larger $\Delta \mathrm{rSO}_{2}$ than patients without CHS [74\% (IQR 67-103) vs. $16 \%$ (IQR -2 to 41 ) and $7 \%$ (IQR 4-15) vs. $1 \%$ (IQR -6 to 7 ), $\mathrm{p}<0.01$, respectively].

Six patients had a postoperative $\Delta V_{\text {mean }}$ of $>100 \%, 4$ patients had a postoperative $V_{\text {mean }}$ of $>120 \mathrm{~cm} \cdot \mathrm{s}^{-1}$ and 2

patients had both. Two of these 12 patients developed CHS. Patients with a postoperative $\Delta V_{\text {mean }}$ of $>100 \%$ or a postoperative $V_{\text {mean }}$ of $>120 \mathrm{~cm} \cdot \mathrm{s}^{-1}$ had a higher $\Delta \mathrm{rSO}_{2}$, i.e. $8 \%$ (IQR 2-15), than patients who had not, i.e. $0 \%$ (IQR -5 to 6 ), $\mathrm{p}=0.019$. The MAP did not change postoperatively compared to preoperative measurements.

\section{Logistic Regression Analysis (table 4)}

Univariate analysis demonstrated that both postoperative $\Delta V_{\text {mean }}$ [odds ratio (OR) 1.40 (95\% CI 1.02-1.93) per $30 \%$ increase] and postoperative $\Delta \mathrm{rSO}_{2}$ [OR $1.82(95 \% \mathrm{CI}$ 1.11-2.99) per 5\% increase] were related to the development of CHS postoperatively.

\section{ROC Curve Analysis (fig. 2)}

Based on ROC curve analysis an increase in $V_{\text {mean }}$ of $67 \%$ was identified as the cutoff value most related to the onset of CHS, with an area under the curve of 0.88 ( $\mathrm{p}=$ 0.001 ). With this cutoff value, a PPV of $38 \%$ and an NPV of $99 \%$ were found (table 5). A cutoff value of $2 \% \mathrm{rSO}_{2}$ increase with an area under the curve of $0.79(\mathrm{p}=0.009)$ had a PPV of $11 \%$ and an NPV of $100 \%$. As shown in table 5 , a combination of both monitoring techniques provides a PPV of $58 \%$ and an NPV of $99 \%$. Of all 15 patients with $\Delta V_{\text {mean }}>67 \%, 9$ patients had a $\Delta \mathrm{rSO}_{2}>2 \%$. 
Table 2. Intraoperative ( $\Delta$ Intra) and postoperative ( $\Delta$ Post) relative changes in MAP, mean MCA blood velocity ( $\left.V_{\text {mean }}\right)$ and frontal lobe oxygenation $\left(\mathrm{rSO}_{2}\right)$ for all patients who developed CHS separately and their symptoms

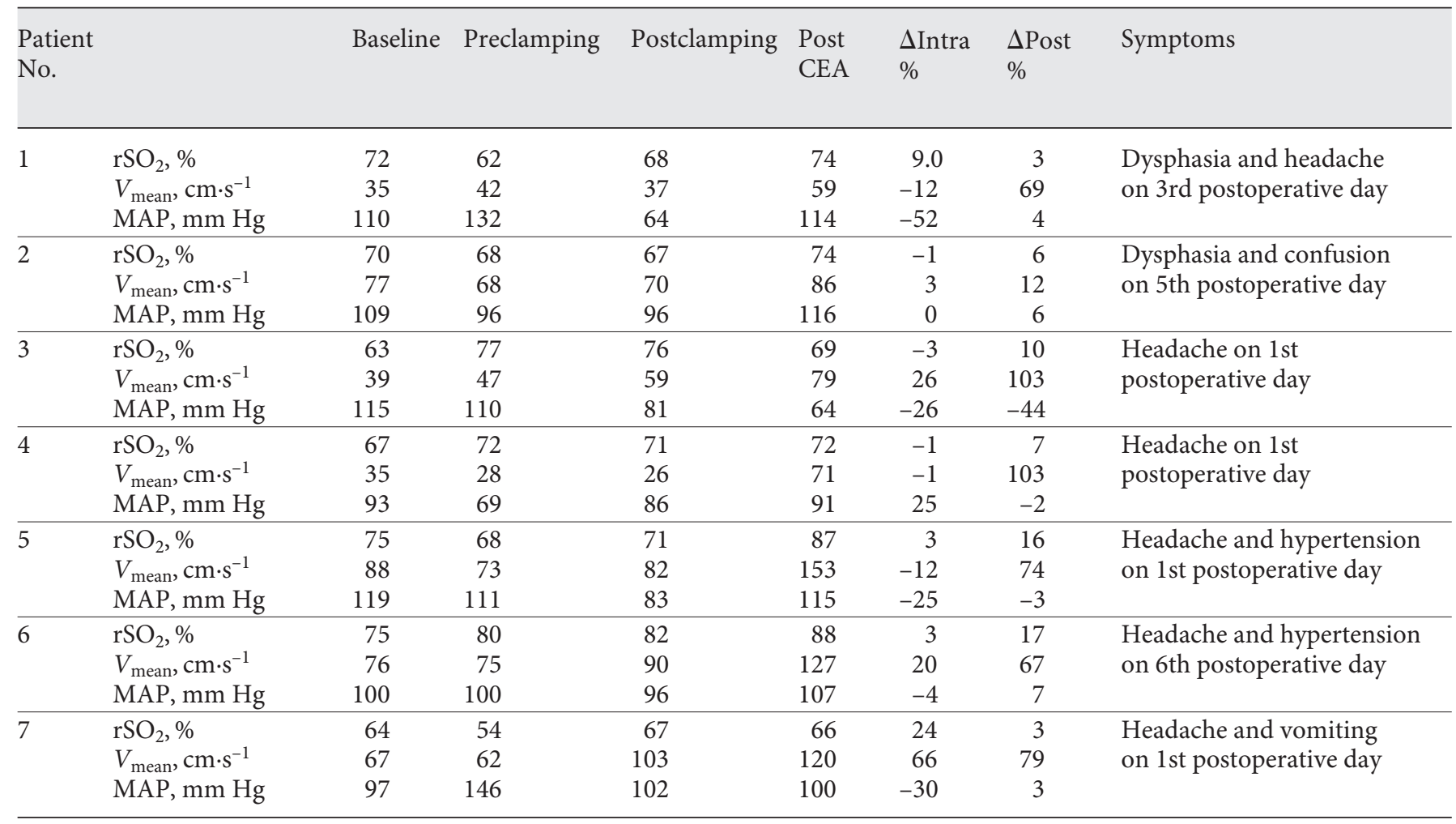

Table 3. Intraoperative and postoperative relative increase in MAP $(\Delta \mathrm{MAP})$, mean MCA blood velocity $\left(\Delta V_{\text {mean }}\right)$ and frontal lobe oxygenation $\left(\Delta \mathrm{rSO}_{2}\right)$ in patients who developed CHS and those who did not

\begin{tabular}{|c|c|c|c|c|c|c|}
\hline & \multicolumn{3}{|c|}{ Intraoperative, $\%$} & \multicolumn{3}{|l|}{ Postoperative, \% } \\
\hline & $\triangle \mathrm{MAP}$ & $\Delta V_{\text {mean }}$ & $\Delta \mathrm{rSO}_{2}$ & $\triangle \mathrm{MAP}$ & $\Delta V_{\text {mean }}$ & $\Delta \mathrm{rSO}_{2}$ \\
\hline CHS $(n=7)$ & $-26(-30$ to 0$)$ & $13(-6$ to 25$)$ & $3(-1$ to 9$)$ & $3(-3$ to 6$)$ & $74(67-102)$ & $7(4-15)$ \\
\hline Non-CHS $(\mathrm{n}=144)$ & $-7(-16$ to 3$)$ & $7(-5$ to 30$)$ & $0(-4$ to 4$)$ & $-16(-27$ to -3$)$ & $16(-2$ to 41$)$ & $1(-6$ to 7$)$ \\
\hline $\mathrm{p}$ value & 0.174 & 0.846 & 0.246 & 0.058 & 0.001 & 0.009 \\
\hline
\end{tabular}

Data are shown as median (IQR).

\section{Discussion}

In this study, we evaluated the relationship between changes in both $\mathrm{rSO}_{2}$ and $V_{\text {mean }}$ during CEA and the development of postoperative CHS. We showed that both $\mathrm{rSO}_{2}$ and $V_{\text {mean }}$ were more increased in patients who did develop CHS than in those who did not. Both measurements could independently relate to the occurrence of CHS. Based on our results, the combination of TCD and
NIRS seems to most reliably select patients at risk for the development of CHS, while NIRS monitoring alone can safely exclude patients at risk of developing CHS.

Exclusion of patients being at risk of developing $\mathrm{CHS}$ is essential as treatment of patients in the early phase can potentially prevent life-threatening symptoms [6]. Several risk factors have been proposed to be associated with the occurrence of CHS, including longstanding hypertension, poor collateral flow high-grade ipsilateral steno- 


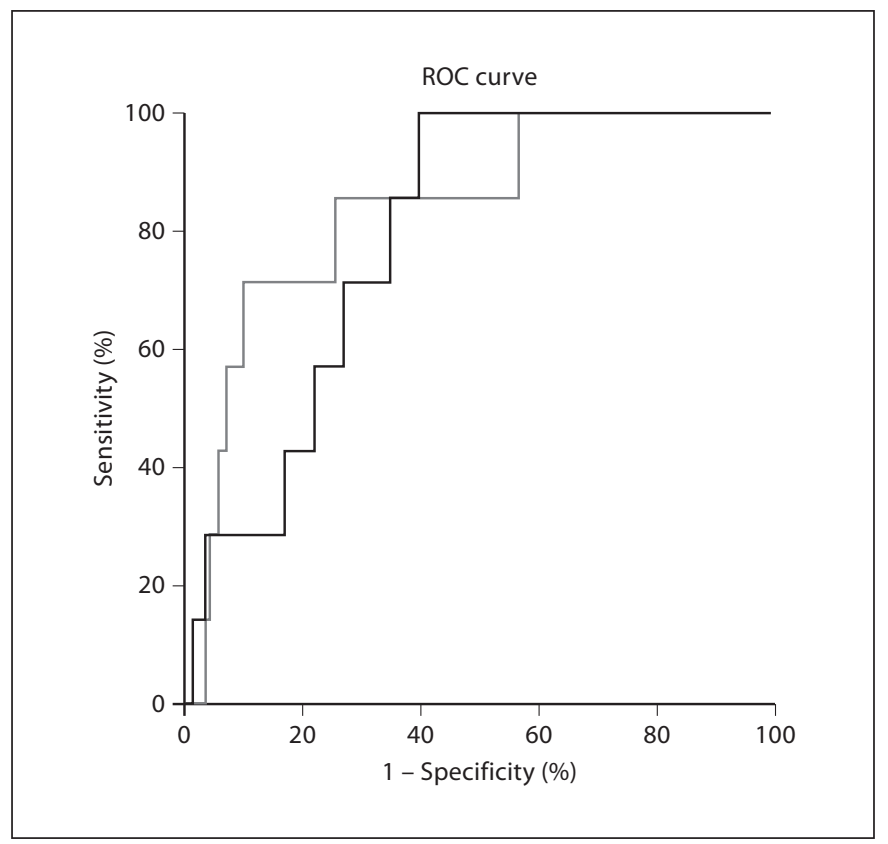

Fig. 2. ROC curves comparing the postoperative increases in relative frontal lobe oxygenation $\left(\mathrm{rSO}_{2}\right.$; dark line) measured using NIRS and TCD-derived mean MCA blood velocity ( $V_{\text {mean }}$; light line) for prediction of CHS following CEA.

sis and contralateral carotid occlusion, but no clear preoperative prediction model exists today [5]. Moreover, both a reduced cerebral blood flow and cerebral vasoreactivity have been shown to be independently related to the onset of CHS $[9,10]$. Increases in cerebral blood flow can be measured using SPECT [11, 12]; however, as this method has several disadvantages including high procedural costs, TCD increase is currently mostly used as a surrogate for cerebral blood flow measurements.

We recently observed that TCD measurements in the postoperative phase more precisely predict the onset of CHS than intraoperative TCD measurements [7]. We attributed this finding to the influence of the administered anesthetic agents during the intraoperative measurement. To avoid the influence of anesthetics on the measurements, we used the same time frame in the current study and compared the preoperative and postoperative awake values.

As described elsewhere, the value of NIRS related to the onset of CHS has been promising, but the evidence is poor since there are no clearly defined $\mathrm{rSO}_{2}$ cutoff values [8]. Ogasawara et al. [13] compared declamping $\mathrm{rSO}_{2}$ with preclamping values and found a significant correlation between $\mathrm{rSO}_{2}$ increases after declamping and the onset of
Table 4. Univariate predictors of the development of CHS

\begin{tabular}{|c|c|c|}
\hline Variable & OR & $95 \% \mathrm{CI}$ \\
\hline Male gender & 1.40 & $0.26-7.56$ \\
\hline Right side & 1.05 & $0.23-4.86$ \\
\hline Age & 0.93 & $0.86-1.01$ \\
\hline \multicolumn{3}{|l|}{ History of CEA } \\
\hline Ipsilateral & 0 & \\
\hline Contralateral & 1.33 & $0.15-11.79$ \\
\hline Symptomatic indication & 0.80 & $0.09-7.08$ \\
\hline \multicolumn{3}{|l|}{ Degree of ipsilateral stenosis } \\
\hline $50-70 \%$ & 2.83 & $0.30-26.45$ \\
\hline$>70 \%$ & 0.13 & $0.04-3.30$ \\
\hline \multicolumn{3}{|l|}{ Degree of contralateral stenosis } \\
\hline$<50 \%$ & 0.42 & $0.08-2.25$ \\
\hline $50-70 \%$ & 0.83 & $0.10-7.24$ \\
\hline $70-99 \%$ & 2.22 & $0.41-12.16$ \\
\hline Occlusion & 1.17 & $0.13-10.26$ \\
\hline Unknown & 2.23 & $0.24-20.41$ \\
\hline Peroperative shunt use & 3.44 & $0.61-19.30$ \\
\hline Intraoperative $\Delta V_{\text {mean }}$, per $1 \%$ increase & 1.00 & $0.98-1.02$ \\
\hline Intraoperative $\Delta \mathrm{rSO}_{2}$, per $1 \%$ increase & 1.10 & $0.92-1.19$ \\
\hline Postoperative $\Delta V_{\text {mean }}$, per $1 \%$ increase & $1.01^{*}$ & $1.00-1.03$ \\
\hline Postoperative $\Delta \mathrm{rSO}_{2}$, per $1 \%$ increase & $1.13^{*}$ & $1.02-1.25$ \\
\hline Postoperative $\Delta V_{\text {mean }}$, per $30 \%$ increase & $1.48^{*}$ & $1.08-2.03$ \\
\hline Postoperative $\Delta \mathrm{rSO}_{2}$, per $5 \%$ increase & $1.82^{*}$ & $1.11-2.99$ \\
\hline
\end{tabular}

Statistically significant predictors of CHS are indicated by an asterisk.

Table 5. Diagnostic cross-table for the number of patients that developed CHS after CEA correctly diagnosed by NIRS and/or TCD measurements

\begin{tabular}{lllll} 
CHS+ CHS- & $\begin{array}{l}\text { Sens. Spec. } \\
\%\end{array}$ & $\begin{array}{l}\text { PPV } \\
\%\end{array}$ & $\begin{array}{l}\text { NPV } \\
\%\end{array}$ \\
\hline
\end{tabular}

Monitoring technique

$\begin{array}{lrrrrrr}\text { NIRS+ } & 7(5) & 59(39) & 100 & 58 & 11 & 100 \\ \text { NIRS- } & 0(0) & 82(5) & & & & \\ \text { TCD+ } & 6(4) & 10(7) & 86 & 93 & 38 & 99 \\ \text { TCD- } & 1(1) & 131(9) & & & & \\ \text { Cmbined monitoring techniques } & & & & \\ \text { TCD+, NIRS+ } & 6(4) & 3(2) & 86 & 98 & 67 & 99 \\ \text { TCD-, NIRS- } & 0 & 74(49) & 0 & 54 & 0 & 10 \\ \text { TCD+ or NIRS+ } & 7(5) & 64(4) & 100 & 46 & 10 & 100\end{array}$

Figures in parentheses are percentages. The cutoff points used are determined after analysis of the ROC curve; it was a $2 \%$ increase for NIRS measured frontal lobe oxygenation $\left(\Delta \mathrm{rSO}_{2}\right)$ and a $67 \%$ increase for TCD-measured MCA blood velocity $\left(\Delta V_{\text {mean }}\right)$.

Sens. $=$ Sensitivity; Spec. $=$ specificity 
CHS. However, in their study, only 1 patient developed CHS. Komoribayashi et al. [14] also used intraoperatively measured NIRS values. They found a significant association between cerebral hyperperfusion, patients without clinical symptoms, and a reduced $\mathrm{rSO}_{2}$ during clamping as compared to preclamping values. Moreover, the association between intraoperative ischemia and cerebral hyperperfusion following CEA has been shown previously [15].

Our study has several limitations. Firstly, early antihypertensive treatment of patients at risk might have prevented the later development of CHS. In 12 patients, cerebral hyperperfusion was observed $\left(\Delta V_{\text {mean }}\right.$ of $>100 \%$, or a postoperative $V_{\text {mean }}$ of $>120 \mathrm{~cm} \cdot \mathrm{s}^{-1}$ ), but only in 8 of these patients an increase in $\mathrm{rSO}_{2}$ of $>2 \%$ was found. $\mathrm{Nev}$ ertheless, the other 4 patients did not develop CHS. This might be explained by the use of antihypertensive therapy in the selected patients. It is thought that patients with a high-degree carotid stenosis have an impaired cerebral autoregulation. As in these patients the cerebrovascular resistance is reduced and the $V_{\text {mean }}$ (as a surrogate measure of the cerebral blood flow) has become BP dependent [16], antihypertensive treatment might have prevented the later development of CHS in these patients. However, in our analysis, we assumed that all hypertensive patients would have developed CHS (worst case scenario). In such a scenario, the magnitude of the ORs remained similar, and therefore we feel that the treatment of hypertension of patients whose blood pressure rose did not affect our findings. Therefore, we conclude that the use of antihypertensive medication has not influenced our results. Secondly, the utility of TCD was limited by the need for a sufficient bone window; moreover, TCD measurements required experienced personnel. NIRS can partly compensate for the disadvantages of TCD, since it is easy to apply and can be performed in all patients. Nevertheless, the interindividual and intraindividual baseline variability is high [17]; therefore, we correlated outcome to the relative and not the absolute change in $\mathrm{rSO}_{2}$. Further- more, the reproducibility of NIRS measurements has previously been questioned [17]. To reduce the interindividual variation, we used NIRS as a trend monitor and to reduce the intraindividual variation, we did not remove the sensor between the end of surgery and the measurement in the recovery room.

The third and most relevant limitation of our study is the limited number of cases. Because of the small number of patients who develop CHS following CEA, this number is not easy to expand. Therefore, we used a limited number of predictors and no adjustment for multiple testing was made. Where the small numbers limited the precision of our estimates, it is unlikely that it affected the validity of our findings.

Based on our results, we conclude that NIRS is a reliable monitoring technique to exclude patients at risk of developing CHS. Furthermore, for the detection of patients at risk of developing CHS, the combination of NIRS and TCD monitoring provides the highest predictive value. However, as increase in the number of cases is needed to confirm our results, it is too premature to recommend a widespread application of use for the detection of patients at risk of developing CHS. Nevertheless it strengthens us to continue the evaluation of both NIRS and TCD and we added NIRS to our standard cerebral monitoring protocol.

\section{Acknowledgements}

Invos Cerebral Oximeter (Somanetics Corporation, Troy, Mich., USA) was costless provided for the duration of the trial by Covidien Nederland B.V., Zaltbommel, The Netherlands.

\section{Disclosure Statement}

None of the authors have a conflict of interest related to this study.

\section{References}

1 Riles TS, Imparato AM, Jacobowitz GR, et al: The cause of perioperative stroke after carotid endarterectomy. J Vasc Surg 1994;19:206214.

-2 de Borst GJ, Moll FL, van de Pavoordt HD, Mauser HW, Kelder JC, Ackerstaf RG: Stroke from carotid endarterectomy: when and how to reduce perioperative stroke rate? Eur J Vasc Endovasc Surg 2001;21:484-489.

\footnotetext{
3 Naylor AR, Hayes PD, Allroggen H, et al: Reducing the risk of carotid surgery: a 7-year audit of the role of monitoring and quality control assessment. J Vasc Surg 2000;32:750-759.

-4 Smith JL, Evans DH, Gaunt ME, London NJ, Bell PR, Naylor AR: Experience with transcranial Doppler monitoring reduces the incidence of particulate embolization during carotid endarterectomy. Br J Surg 1998;85: 56-59.
}

\footnotetext{
5 van Mook WN, Rennenberg RJ, Schurink GW, et al: Cerebral hyperperfusion syndrome. Lancet Neurol 2005;4:877-888.

-6 Dalman JE, Beenakkers IC, Moll FL, Leusink JA, Ackerstaff RG: Transcranial Doppler monitoring during carotid endarterectomy helps to identify patients at risk of postoperative hyperperfusion. Eur J Vasc Endovasc Surg 1999;18:222-227.
} 
7 Pennekamp CW, Tromp SC, Ackerstaff RG, et al: Prediction of cerebral hyperperfusion after carotid endarterectomy with transcranial Doppler. Eur J Vasc Endovasc Surg 2012; 43:371-376.

8 Pennekamp CWA, Bots ML, Kappelle LJ, Moll FL, De Borst GJ: The value of near-infrared spectroscopy measured cerebral oximetry during carotid endarterectomy in perioperative stroke prevention. A review. Eur J Vasc Endovasc Surg 2009;38:539-545.

$\checkmark 9$ Hosoda K, Kawaguchi T, Ishii K, et al: Prediction of hyperperfusion after carotid endarterectomy by brain SPECT analysis with semiquantitative statistical mapping method. Stroke 2003;34:1187-1193.

10 Ogasawara K, Yukawa H, Kobayashi M, et al: Prediction and monitoring of cerebral hyperperfusion after carotid endarterectomy by using single-photon emission computerized tomography scanning. J Neurosurg 2003;99:504-510.
11 Chida K, Ogasawara K, Aso K, et al: Postcarotid endarterectomy improvement in cognition is associated with resolution of crossed cerebellar hypoperfusion and increase in 123I-iomazenil uptake in the cerebral cortex: a SPECT study. Cerebrovasc Dis 2010;29: 343-351.

12 Fujimura M, Inoue T, Shimizu H, Saito A, Mugikura S, Tominaga T: Efficacy of prophylactic blood pressure lowering according to a standardized postoperative management protocol to prevent symptomatic cerebral hyperperfusion after direct revascularization surgery for moyamoya disease. Cerebrovasc Dis 2012;33:436-445.

-13 Ogasawara K, Konno H, Yukawa H, Endo H, Inoue $\mathrm{T}$, Ogawa $\mathrm{A}$ : Transcranial regional cerebral oxygen saturation monitoring during carotid endarterectomy as a predictor of postoperative hyperperfusion. Neurosurgery 2003;53:309-314.
14 Komoribayashi N, Ogasawara K, Kobayashi M, Saitoh H, Terasaki K, Inoue T, Ogawa A: Cerebral hyperperfusion after carotid endarterectomy is associated with preoperative hemodynamic impairment and intraoperative cerebral ischemia. J Cereb Blood Flow Metab 2006;26:878-884.

15 Kawamata T, Okada Y, Kawashima A, et al: Postcarotid endarterectomy cerebral hyperperfusion can be prevented by minimizing intraoperative cerebral ischemia and strict postoperative blood pressure control under continuous sedation. Neurosurgery 2009;64: 447-453.

16 Reinhard M, Muller T, Guschlbauer B, Timmer J, Hetzel A: Dynamic cerebral autoregulation and collateral flow patterns in patients with severe carotid stenosis or occlusion. Ultrasound Med Biol 2003;29:1105-1113.

17 Highton D, Elwell C, Smith M: Noninvasive cerebral oximetry: is there light at the end of the tunnel? Curr Opin Anaesthesiol 2010;23: 576-581. 